\title{
MODALIDADES DE ENXERTIA PARA MARACUJAZEIRO: AVALIAÇÃO PRELIMINAR NAS CONDIÇÕES DA DEPRESSÃO CUIABANA ${ }^{1}$
}

\author{
GIVANILDO RONCATTO², JANAINA BATISTA LENZA ${ }^{3}$, JOÃO PEDRO VALENTE ${ }^{4}$
}

RESUMO - O objetivo do trabalho foi avaliar duas modalidades de enxertia para a cultura do maracujazeiro nas condições da Depressão Cuiabana. O ensaio foi realizado no viveiro da Fazenda Experimental da Faculdade de Agronomia e Medicina Veterinária - FAMEV, da Universidade Federal de Mato Grosso, localizada no município de Santo Antônio do Leverger. Foram utilizadas modalidades de enxertia do tipo garfagem em fenda cheia e fenda lateral, em três pontos distintos dos porta-enxertos: acima da inserção das primeiras folhas ou enxertia de topo, acima de três folhas e acima de cinco folhas. As mudas utilizadas como porta-enxerto foram obtidas através de sementes oriundas do IAC (Instituto Agronômico de Campinas - SP) da cultivar IAC 275 e do acesso Roxinho-miúdo. Os garfos usados como enxertos foram retirados de plantas jovens da cultivar IAC 275 , com três meses de idade e diâmetro de $0,5 \mathrm{~cm}$. A percentagem de pegamento da enxertia e o desenvolvimento de plantas foram superiores pelo método de garfagem em fenda cheia, sendo também maiores em porta-enxertos com cinco folhas, em relação aos de três e aos sem folhas. A garfagem em fenda cheia mostrou-se mais adequada, uma vez que, com essa modalidade, obtiveram-se $98 \%$ de pegamento.

Termos para indexação: IAC 275, fenda cheia, fenda lateral, Passiflora edulis.

\section{PRELIMINARY EVALUATION OF DIFFERENTS GRAFTING METHODS OF PASSION FRUITS TREE UNDER CUIABÁ DEPRESSION CONDITIONS}

ABSTRACT - This study was carried out to evaluate the two grafting methods to the culture of the passion fruit tree under Cuiabá depression conditions. The essay was done at Experimental Farm nursery of the Agronomy and Veterinary Medicine Faculty - FAMEV of the Mato Grosso Federal University, located in Santo Antônio do Leverger town, in Brazil. It was used grafting methods type of full cleft grafting and lateral grafting, in three points in the rootstock: the top of the plant, above of three leafs and above of five leafs. The seedlings used like rootstocks were resultant of seeds came from Agronomic Institute of Campinas - IAC (Sao Paulo, Brazil) of the cultivar IAC 275 of the access Roxinho miúdo. The saddle grafting was taken from seedlings with three months old year, $0.5 \mathrm{~cm}$ of the diameter, of the cultivated IAC 275 . It was used 15 plants in each grafting method, 30 plants in total. The full cleft grafting method has shown better results in the plant growing. And to the rootstock the better results were found above 5 leafs than above 3 leafs or on the top of the plant. The full cleft grafting and saddle grafting in the rootstock got $98 \%$ of success, concluding that it was the most adequate technique.

Index terms: 'IAC 275'; full cleft grafting; lateral grafting; Passiflora edulis.

O maracujazeiro é originário da América Tropical e possui mais de 150 espécies nativas do Brasil. As mais conhecidas e de maior exploração comercial são Passiflora edulis Sims f. flavicarpa Degener e $P$. edulis Sims, sendo também $P$. nitida um pouco conhecida, e a $P$. alata possui $4 \%$ da área cultivada (ALEXANDRE et al., 2004).
O Brasil é o maior produtor de maracujá, alcançando $70 \%$ da produção mundial, seguido pelo Peru, Venezuela, África do Sul, Sri Lanka e Austrália. Destaca-se como uma das principais frutíferas do País, produzindo 684.376 toneladas de frutos (IBGE, 2009). A área plantada é de cerca de 49 mil hectares, destacando-se os Estados da Bahia, Ceará,

${ }^{1}$ (Trabalho 020-10). Recebido em: 05-01-2010. Aceito para publicação em: 01-06-2010. Financiado pela Fundação de Amparo à Pesquisa do Estado de Mato Grosso (Fapemat).

${ }^{2}$ Pesquisador A da Embrapa Mato Grosso. Avenida das Itaúbas, 3257 - Setor Comercial, Cep 78550-194, Sinop - MT. E-mail: givanildoroncatto@ig.com.br

${ }^{3}$ Professora da Universidade de Cuiabá (UNIC) Av. Beira Rio, 3100 Cep 78015480 Cuiabá - MT. E-mail: lenzamaracuja@gmail.com ${ }^{4}$ Professor da Universidade Federal de Mato Grosso (UFMT). Av. Fernando Correa da Costa, s/n Coxipó, Cep 78060900 Cuiabá-MT. E-mail: jdfac@terra.com.br 
São Paulo, Sergipe, Espírito Santo, Pará e Minas Gerais. O Estado de Mato Grosso, com apenas 1\% da produção nacional, ainda não tem uma produção significativa (IBGE, 2009), porém apresenta grande potencial para produção e está em fase de expansão o seu cultivo nos municípios do norte do Estado.

Os pomares de maracujazeiros têm-se expandido em função do preço do produto, sendo este comercializado $50 \%$ in natura e $50 \%$ industrializado como polpa, suco concentrado, néctar pronto para beber, dentre outros produtos. Cultivado também com fins medicinais, para extração de substâncias químicas de propriedades farmacêuticas, como a passiflorina ou maracujina, que é um calmante natural. Seu valor ornamental está associado às flores, coloridas e perfumadas. O maracujá-amarelo tem maior importância comercial devido à qualidade dos frutos, à divulgação junto aos consumidores e ao rendimento industrial, representando $95 \%$ dos pomares brasileiros, O maracujá-doce (P. alata), apesar da menor representatividade, atinge preços unitários mais expressivos no segmento das frutas frescas (BERNACCI et al., 2003; MELETTI; MAIA, 1999).

A propagação do maracujazeiro-amarelo é realizada por sementes, e devido às características inerentes ao método, a maioria dos pomares de maracujazeiros é desuniforme, em termos de produção e qualidade dos frutos obtidos, o que contribui para a baixa produtividade nacional, de $10 \mathrm{t} \mathrm{ha}^{-1} \mathrm{ano}^{-1}$. Outro fator é a dificuldade em utilizar híbridos, variedades e seleções regionais de maracujazeiro para o cultivo, pois poucos materiais são comercializados e disponibilizados aos produtores, constando de registro no órgão regulamentador (MELETTI et al., 2005).

A enxertia é uma forma de propagação vegetativa, que pode contribuir para a implantação de pomares tecnicamente superiores, comparados àqueles formados por sementes, seja em função do controle de doenças, principalmente a morte prematura de plantas,seja através de porta-enxertos resistentes/ tolerantes (P. nitida, P. gibertii, P. setacea, P. alata), além de proporcionar multiplicação de plantas mais produtivas e com frutos de qualidade, obtendo-se pomares menos heterogêneos e com resistência a pragas e a doenças (MENEZES, 1990; RUGGIERO; OLIVEIRA, 1998; RONCATTO et al., 2004). A escolha criteriosa do porta-enxerto no uso da enxertia deve proporcionar especificidades como tolerância à morte prematura em espécies de passifloras como: P. gibertii, $P$. alata, $P$. setacea, $P$. macrocarpa, na multiplicação de plantas de qualidade.

A enxertia do maracujazeiro já foi testada em outros locais, como é o caso de Jaboticabal- SP, Distrito Federal, Cruz das Almas-BA, sob condi- ções climáticas diferentes das de Santo Antônio do Leveger (Depressão Cuiabana). Vários autores já estudaram, dentro da propagação por enxertia, o índice de pegamento em muitas espécies, sendo alguns deles: Menezes et al. (1994), Chaves et al. (2004), Nogueira Filho et al. (2005), Silva et al. (2005) e Junqueira et al. (2006). No entanto, os resultados são conflitantes, muitas vezes ficando abaixo das expectativas, principalmente naquelas espécies silvestres, como $P$. gibertii N.E.Brown ou maracujá-de-veado, $P$. nitida H.B.K. ou maracujá-do-mato e $P$. setacea D.C., necessitando de novos estudos para viabilizar a enxertia. As espécies silvestres $P$. caerulea L., $P$. gibertii, $P$. alata e $P$. nitida apresentaram até $90 \%$ de pegamento na enxertia, sendo que, nas espécies P. edulis e $P$. edulis f. flavicarpa, os resultados são mais promissores, alcançando $100 \%$ de pegamento, pois existe maior afinidade quando a enxertia é feita sobre a própria espécie (MENEZES, 1990; MENEZES et al., 1994).

Já Lima et al. (1999) conseguiram melhor pegamento quando utilizaram $P$. caerulea e $P$. cincinnata, alcançando $75 \%$ de pegamento. Na enxertia hipocotiledonar, a espécie $P$. setacea teve baixo pegamento ( $30 \%$ de pegamento), tendo obtido resultado excelente em $P$. cincinnata, $P$. gibertii e $P$. edulis $\mathrm{f}$. flavicarpa, alcançando $100 \%$ de pegamento. No $P$. alata, $P$. caerulea e $P$. coccínea, o resultado também foi bom, superior a $70 \%$ de pegamento (NOGUEIRA FILHO, 2003; NOGUEIRA FILHO et al., 2005).

Este trabalho teve como objetivo avaliar duas modalidades de enxertia de maracujazeiros, no viveiro da Fazenda Experimental da Faculdade de Agronomia e Medicina Veterinária da Universidade Federal de Mato Grosso (FAMEV/UFMT), localizada no município de Santo Antônio do Leverger, na Depressão Cuiabana, a $15^{\circ} 47^{\prime} 11^{\prime}$ 'S de latitude, $56^{\circ} 04^{\prime} 17^{\prime}$ ' W de longitude e a uma altitude de $140 \mathrm{~m}$. De acordo com a classificação de Köeppen, o clima na região é do tipo Aw ou Tropical de savana, com períodos distintos de secas e chuvas. A temperatura média anual situa-se em torno de $26^{\circ} \mathrm{C}$, precipitação de $1.360 \mathrm{~mm}$ e umidade relativa do ar em torno de 66\% (MIRANDA; AMORIM, 2000).

Os porta-enxertos foram obtidos de sementes oriundas do IAC (Instituto Agronômico de Campinas - SP), da cultivar híbrida de polinização controlada, pelo produtor de sementes, o IAC 275 e da espécie Passiflora edulis Sims (acesso Roxinhomiúdo). As estacas para enxerto foram adquiridas de plantas juvenis, com três meses de idade, do 'IAC 275', onde se utilizaram 15 plantas para testar cada modalidade, totalizando 30 plantas em avaliação. Foram testadas duas modalidades de enxertia: gar- 
fagem em fenda cheia e lateral. Utilizaram-se três pontos distintos do porta-enxerto: acima da inserção das primeiras folhas (enxertia de topo), acima de três folhas e acima de cinco folhas.

$\mathrm{Na}$ fenda cheia, as mudas oriundas de sementes para porta-enxerto foram decapitadas na altura do ponto de enxertia ( $15 \mathrm{~cm}$ de altura) da haste principal, onde foi inserido um enxerto em forma de cunha, com duas gemas, e retirando-se as folhas. A técnica de garfagem por fenda cheia consistiu na inserção do enxerto no porta-enxerto, preparado com um corte longitudinal ao caule, com auxílio de uma lâmina de platina. No local decapitado, foi inserido o enxerto com a base preparada em forma de cunha. O local foi amarrado com fita de enxertia, sendo utilizada uma câmara úmida, com uso de um saco plástico transparente $(23 \mathrm{~cm} \mathrm{x} 4 \mathrm{~cm})$, individualmente, sobre a muda enxertada, até que se verificasse o efetivo pegamento, diminuindo assim a evapotranspiração.

A garfagem lateral é a forma de enxertia mais simples por garfagem e consistiu em efetuarse um corte a partir da superfície da casca, com a finalidade de descobrir o câmbio, tanto no enxerto quanto no porta-enxerto, abrindo-se uma fenda lateral, no sentido do raio, até atingir o câmbio a aproximadamente $2 \mathrm{~cm}$, no sentido do comprimento do porta-enxerto. $\mathrm{O}$ garfo foi preparado na forma de bisel e introduzido na incisão. Depois, unem-se essas superfícies com fita de enxertia. Quando a união estiver completamente formada, faz-se o corte da parte aérea do porta-enxerto, de tal maneira que a nova planta fique constituída do sistema radicular e da copa das cultivares desejadas. O bisel teve aproximadamente o mesmo comprimento da incisão lateral. Após a inserção do garfo na fenda e feito o amarrio com fita de enxertia, foi colocado sobre o mesmo um saco plástico transparente para a formação da câmara úmida, até que se efetivasse o pegamento.

Avaliou-se o desenvolvimento das plantas, medindo-se a altura das plantas a cada cinco dias, durante um período de 30 dias, a partir dos 10 dias da enxertia, a fim de obter-se a avaliação do vigor das mudas através do comprimento da mesma. A taxa de pegamento foi calculada com base na contagem dos enxertos pegos, após 10; 20 e 30 dias da execução da enxertia, os quais foram transformados em percentagens. O delineamento experimental utilizado foi o inteiramente casualizado no esquema fatorial $2 \times 2 \times 3$, sendo os fatores porta-enxerto (IAC 275 e Roxinho-miúdo), modalidade de garfagem (fenda cheia e lateral) e três pontos distintos de enxertia (topo, acima de três e acima de cinco folhas), com 15 plantas de cada modalidade de enxertia, totalizando 30 plantas. Os resultados obtidos foram analisados estatisticamente, com o uso do software SPSS 10 (SPSS 10, 2000).

Para as plantas enxertadas através do método de fenda cheia, o valor médio de crescimento foi de $4 \mathrm{~cm}$ a cada cinco dias, enquanto na fenda lateral a média foi de $2,3 \mathrm{~cm}$. A percentagem de pegamento da enxertia foi significativamente superior por fenda cheia com $98 \%$ em relação à fenda lateral, com 70\%, aos 30 dias após a enxertia (Figura 1). Estes dados estão de acordo com os obtidos por Ruggiero e Corrêa (1980), em Jaboticabal-SP, que utilizaram fenda cheia e inglês simples, com pegamento superior a $90 \%$ na fenda cheia. Chaves et al. (2004) e Silva et al. (2005) conseguiram percentagem de 98\% de pegamento, utilizando enxertia por fenda cheia em porta-enxerto por estaca.

Menezes et al. (1994) obtiveram até 100\% de pegamento na enxertia. Da mesma forma, Nogueira Filho et al. (2005) alcançaram 100\% nos índices de pegamento, mas utilizando-se de enxertia hipocotiledonar. Considerando a ampla diversidade de porta-enxertos utilizada por esses autores, em comparação com o presente trabalho, foi no maracujazeiro-amarelo como porta-enxerto que as taxas de pegamento foram superiores.

Com relação à ausência ou à presença de folhas, a taxa de pegamento foi significativamente superior, com cinco folhas $(41 \%)$, em relação a três folhas $(36 \%)$ ou com nenhuma folha $(23 \%)$, utilizando-se do método por fenda cheia. Atribui-se esse resultado à área foliar, possibilitando maior atividade fotossintética, auxiliando no êxito da enxertia.

A análise de regressão para as modalidades de enxertia revelou a existência de uma correlação significativa, a 5\% de probabilidade, com um coeficiente de determinação > 0,96 (Figura 2). Houve melhor definição do sucesso da enxertia aos 30 dias após a sua execução; provavelmente, aos 10 e 20 dias, as gemas do enxerto ainda estavam dormentes. A regressão foi linear para as duas modalidades, ou seja, o índice de pegamento do maracujazeiro, ao longo do tempo, foi crescente aos 10; 20 e 30 dias após a enxertia, sendo superior na modalidade fenda cheia quando comparado ao da fenda lateral.

Conclui-se que a enxertia pela modalidade de garfagem por fenda cheia, em porta-enxertos de cinco folhas, foi a mais eficaz, pois resultou numa taxa de 98\% de pegamento dos enxertos de 'IAC 275' sobre o Roxinho-miúdo aos 30 dias após a enxertia. 


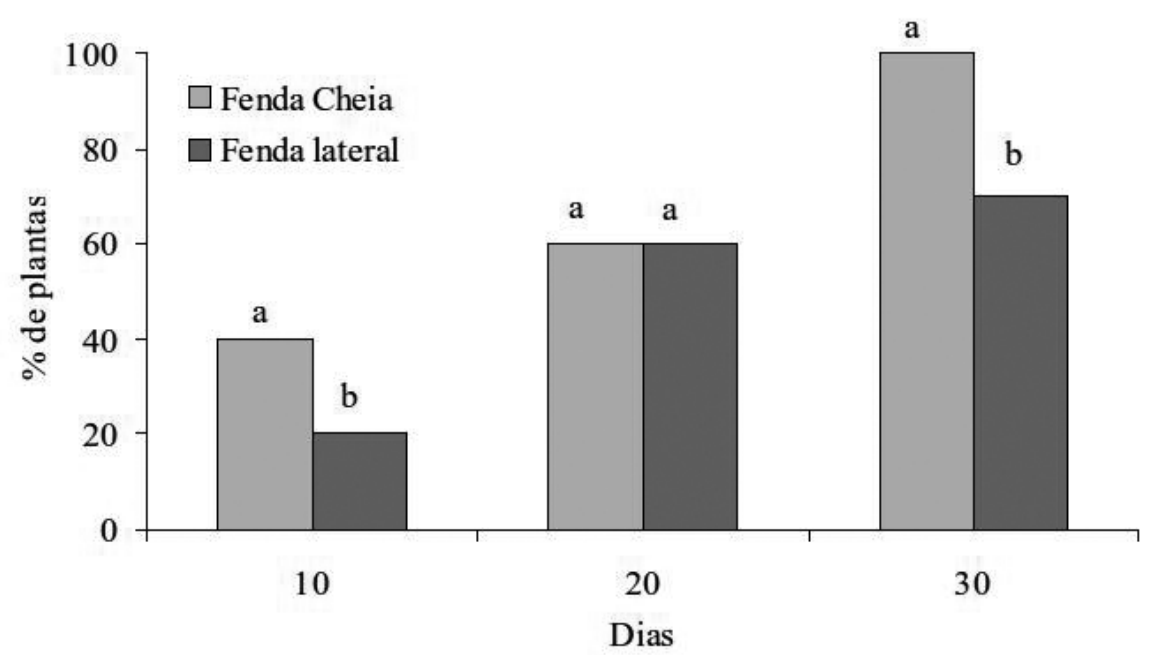

FIGURA 1-Percentagem de pegamento aos 10; 20 e 30 dias após a enxertia do maracujazeiro. Letras iguais não diferem entre si, na mesma data, pelo teste de Tukey, a 5\% de probabilidade.

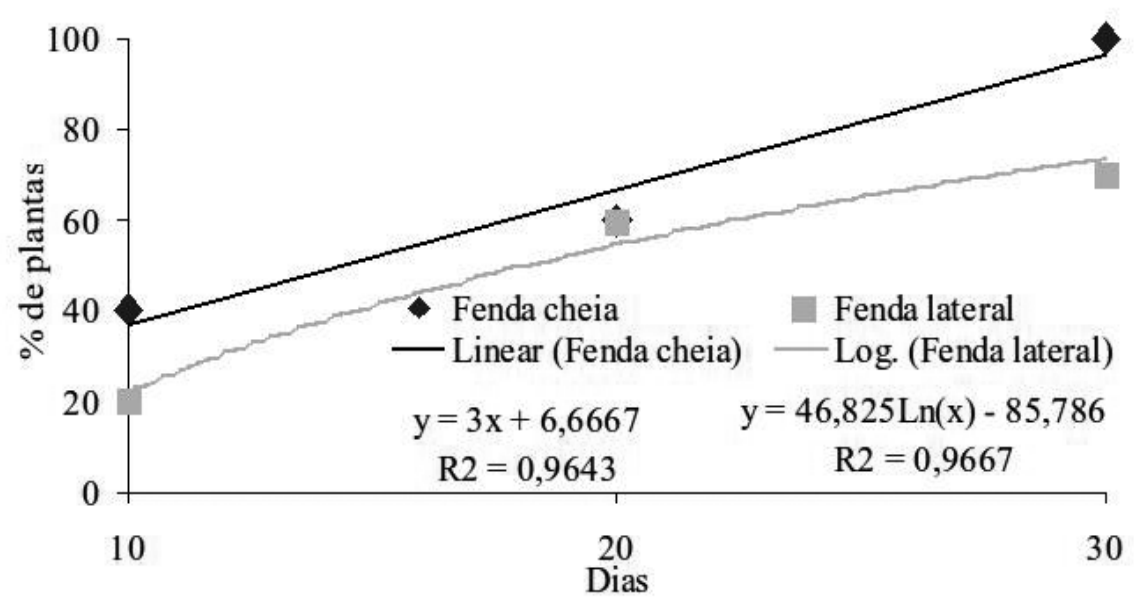

FIGURA 2 - Percentagem de pegamento de mudas enxertadas de maracujazeiro em três datas: 10; 20 e 30 dias após a enxertia.

\section{REFERÊNCIAS}

ALEXANDRE, R.S.; WAGNER JÚNIOR, A.; NEGREIROS, J.R. DA S.; PARIZZOTTO, A.; BRUCKNER, C.H. Germinação de sementes de genótipos de maracujazeiro. Pesquisa Agropecuária Brasileira, Brasília, v.39, n.12, p.1239-1245, 2004.

BERNACCI, L. C.; MELETTI, L. M. M.; SOARESSCOTT, M. D. Maracujá-doce: o autor, a obra e a data da publicação de Passiflora alata (Passifloraceae) Revista Brasileira de Fruticultura, Jaboticabal , v.25 n.2 p. 102-105, 2003.
CHAVES, R. da C.; JUNQUEIRA, N.T.V.; MANICA, I.; PEIXOTO, J.R.; PEREIRA, A.V.; FIALHO, J. DE F. Enxertia de maracujazeiro-azedo em estacas herbáceas enraizadas de espécies de passifloras nativas. Revista Brasileira de Fruticultura, Jaboticabal, v.26, n.1, p.120-123, 2004.

IBGE - Instituto Brasileiro de Geografia e Estatística. Produção Agrícola Municipal. Maracujá. Brasília: Ministério do Planejamento, Orçamento e Gestão, 2009. Disponível: $<$ http://www.sidra.ibge.gov.br/ bda/tabela/protabl.asp? $\mathrm{z}=\mathrm{t} \& \mathrm{o}=10 \& \mathrm{i}=\mathrm{P}>$. Acesso em: 11 nov. 2009. 
JUNQUEIRA, N.T.V.; LAGE, D.A. da C.; BRAGA, M.F.; PEIXOTO, J.R.; BORGES, T.A.; ANDRADE, S.R.M. de. Reação a doenças e produtividade de um clone de maracujazeiro-azedo propagado por estaquia e enxertia em estacas herbáceas de Passiflora silvestre. Revista Brasileira de Fruticultura, Jaboticabal, v.28, n.1, 2006.

LIMA, A. de A.; CALDAS, R.C.; CUNHA, M.A.P.; SANTOS FILHO, H.P. Avaliação de porta-enxertos e tipos de enxertia para o maracujá-amarelo. Revista Brasileira de Fruticultura, Jaboticabal, v.21, n.3, p.318-321, 1999.

MELETTI, L. M. M.; MAIA, M. L. Maracujá: produção e comercialização. Campinas: Instituto Agronômico, 19998. p. 64. ( Boletim Técnico, 181)

MELETTI, L.M.M.; SOARES-SCOTT, M.D.; BERNACCI, L.C.; PASSOS, I.R. da S. Melhoramento genético do maracujá: passado e futuro In: FALEIRO, F.G.; JUNQUEIRA, N.T.V.; BRAGA, M.F. (Ed.). Maracujá: germoplasma e melhoramento genético. Planaltina: Embrapa Cerrados, 2005. p.341-358.

MENEZES, J. M. T. Seleção de porta-enxertos tolerantes à morte prematura de plantas para $\boldsymbol{P}$. edulis Sims f. flavicarpa Deg. e comportamento de P. nitida H.B.K. na região de Jaboticabal. 1990. 73 f. Dissertação (Mestrado em Melhoramento Genético Vegetal) -Faculdade de Ciências Agrárias e Veterinárias, Universidade Estadual Paulista, Jaboticabal, 1990.

MENEZES, J.M.T.; OLIVEIRA, J.C. de; RUGGIERO, C.; BANZATTO, D. A. Avaliação da taxa de pegamento de enxertos de maracujá-amarelo sobre espécies tolerantes à "morte prematura de plantas". Científica, Jaboticabal, v.22, n.1, p.95-104, 1994.

MIRANDA, L.; AMORIM, L. Mato Grosso: atlas geográfico. Cuiabá: Entrelinhas, 2000.
NOGUEIRA FILHO, G.C. Competição de sete espécies de maracujazeiro propagadas por enxertia hipocotiledonar. 2003. 95f. Tese (Doutorado em Agronomia, Área de Produção Vegetal) - Faculdade de Ciências Agrárias e Veterinárias, Universidade Estadual Paulista, Jaboticabal, 2003.

NOGUEIRA FILHO, G.C.; RONCATTO, G.; RUGGIEIRO, C.; OLIVEIRA, J.C. de; MALHEIROS, E.B. Propagação vegetativa do maracujazeiro-conquista de novas adesões. In: FALEIRO, F.G.; JUNQUEIRA, N.T.V.; BRAGA, M.F. (Eds.). Maracujá: germoplasma e melhoramento genético. Planaltina: Embrapa Cerrados, 2005. p.341-358.

RONCATTO, G.; OLIVEIRA, J.C. de; RUGGIERO, C.; NOGUEIRA FILHO, G.C.; CENTURION, M.A.P. da C.; FERREIRA, F. R. Comportamento de maracujazeiros (Passiflora spp.) quanto à morte prematura. Revista Brasileira de Fruticultura. Jaboticabal, v.26, n.3, p.552-554, 2004.

RUGGIERO, C.; CORRÊA, L. S. Implantação da cultura e propagação. In: RUGGIERO, C. Cultura do maracujazeiro. Jaboticabal: Faculdade de Ciências Agrárias e Veterinárias, UNESP, 1980. p.23-31.

RUGGIERO, C.; OLIVEIRA, J. C. de Enxertia do maracujazeiro. In: SIMPÓSIO BRASILEIRO SOBRE A CULTURA DO MARACUJAZEIRO, 5. 1998. Anais... Jaboticabal: FUNEP, 1998. p.70-92.

SILVA, F. M.; CORREA, L. de S.; BOLIANI, A. C.; SANTOS, P.C. dos. Enxertia de mesa de Passiflora edulis Sims f. flavicarpa Deg. sobre Passiflora alata Curtis, em ambiente de nebulização intermitente. Revista Brasileira de Fruticultura, Jaboticabal, v.27, n.1, p.98-101, 2005.

STATISTICAL PACKAGE FOR THE SOCIAL SCIENCES - SPSS for Windows. Base user's guide, release 10. Chicago, 2000. 